\title{
Is there a social gradient in how youth with mental disorder perform academically? Findings from a Swedish longitudinal register-based study
}

\author{
Evelina Landstedt ${ }^{1,2,3^{*}}$ (D) Cristian Bortes ${ }^{2}$ and Mattias Strandh ${ }^{2}$
}

\begin{abstract}
Background: It is well established that academic achievement and other school-related outcomes are associated with mental health status in children and youths. However, few studies have examined the influence of socioeconomic background on the relationship between poor childhood/adolescent mental health and school performance. From an equity perspective, it is important to explore how school-related outcomes are affected for young people with mental disorder and if these outcomes differ depending on gender and socioeconomic background. This study aimed to investigate social gradients in the prospective association between childhood/ adolescent mental disorder and academic achievement.

Methods: This register based study used data from the Umeå SIMSAM Lab of linked Swedish registers on all children born between 1990 and 1994 and their parents ( $N=642$ 558). The outcome was school grades achieved upon compulsory school graduation (age 15/16). Mental disorder was indicated by number of hospitalisations due to ICD classified mental disorders and prescription of psychoanaleptic drugs. Indicators of socioeconomic position were parental level of education and family income in four categories respectively. Parental history of mental disorder was controlled for. Linear regressions, including interaction analyses, were performed.

Results: Mental disorder in childhood/adolescence was related to lower grades, particularly in boys. The drop in academic achievement among youth with mental disorder was more pronounced among girls in mid SEP categories than among their less and more advantaged peers. A less clear interaction pattern was identified in boys.

Conclusions: Based on theory and existing research we expected a typical social gradient in the strength of the association between mental disorder and academic achievement. However, we identified a U-shaped social gradient among girls. Analyses of the links between mental health and academic outcomes need to take both gender and social position into account. More research is needed to investigate these patterns further.
\end{abstract}

Keywords: Mental Health, Academic Achievement, Social Gradient, Registry Data, Adolescents, Gender

\footnotetext{
* Correspondence: evelina.landstedt@kau.se

${ }^{1}$ Department of Social and Psychological Studies, Karlstad University,

Universitetsgatan 2, SE-651 88 Karlstad, Sweden

2Department of Social Work, Umeå University, SE-907 87 Umeå, Sweden

Full list of author information is available at the end of the article
}

(c) The Author(s). 2021, corrected publication 2021. Open Access This article is licensed under a Creative Commons Attribution 4.0 International License, which permits use, sharing, adaptation, distribution and reproduction in any medium or format, as long as you give appropriate credit to the original author(s) and the source, provide a link to the Creative Commons licence, and indicate if changes were made. The images or other third party material in this article are included in the article's Creative Commons licence, unless indicated otherwise in a credit line to the material. If material is not included in the article's Creative Commons licence and your intended use is not permitted by statutory regulation or exceeds the permitted use, you will need to obtain permission directly from the copyright holder. To view a copy of this licence, visit http://creativecommons.org/ licenses/by/4.0/. The Creative Commons Public Domain Dedication waiver (http://creativecommons.org/publicdomain/zero/1. 0/) applies to the data made available in this article, unless otherwise stated in a credit line to the data. 


\section{Background}

Poor mental health in children and adolescents include anxiety and depressive symptoms, as well as mental disorders [1]. Beyond its detrimental effects on the individual's quality of life, poor mental health in childhood is a major risk factor for future short- and long-term mental health problems, as well as other adverse social, educational and work-related outcomes [2-6]. Accordingly, it has been shown that self-rated health status in adults is associated with access to health-related and material resources in childhood, and is influenced by (among other things) school factors in youth [7, 8]. Clearly, school is highly important for young people's general well-being and for establishing future opportunities. Understanding the relationship between mental health and school achievement is key in this regard, particularly given the current deterioration in both mental health and school results in Sweden and worldwide [9-13]. Increasing income inequality in Sweden [14] further calls for research into circumstances early in life that can influence future health as well as social and economic outcomes, for the individual as well as society. Consequently, from an equity perspective, it is important to explore how school-related outcomes are affected when young people are in distress and if these outcomes differ depending on gender and socioeconomic background.

It is well established that academic achievement and other school-related outcomes are associated with mental health status in children and youths [15-17] as well as young university students [18]. However, due to the predominance of cross-sectional studies, the direction of the association is unclear. Nevertheless, based on longitudinal analyses, several models have been proposed in order to understand this relationship. According to the academic-incompetence model, poor academic performance is related to later mental health problems [17, 19]. The adjustment-erosion model, on the other hand, suggests that adolescents with poor mental health perform worse in school than their mentally well peers $[5,17,20$, 21 . Others propose a cascade process of the interplay between internalising and externalising problems in relation to academic difficulties across time [22-24]. A possible contributor to the inconsistencies regarding direction of associations is the vast range of measures applied to reflect different dimensions of poor mental health as well as educational outcomes [23]. Most research also rely on self-reported or parent (or teacher) assessed data on both mental health problems and academic achievement [21, 23, 25-28]. Only a few studies within the field are based on information from registers [29-31]. We argue that it is of value to utilise non-self reported data in exploring the longitudinal relationship between poor mental health in childhood and adolescence, and later academic achievement. Apart from possibly avoiding risk of reporting bias, register data also provide information on more severe mental health problems than is typically investigated in relation to academic achievement, from a large number of individuals.

Although both child/adolescent mental health status and academic achievement are gendered and socially patterned [32-36], there is a knowledge gap relating to gendered and social gradients in the relationship between poor mental health and academic achievement. Some evidence suggests that the association is stronger in girls than in boys $[17,19,37,38]$. Others argue that associations depend on types of symptoms and age $[15,25]$. The role of socioeconomic factors, such as parental level of education and income, is even less explored. The limited evidence available suggest that socioeconomic factors are stronger predictors of academic achievement than various health indicators [39] and that children of low socioeconomic background are disadvantaged both academically and mental health wise [26]. Findings indicate that strong family resources (both cultural and economic) and high neighbourhood socioeconomic status can compensate for the negative impact of mental distress on school achievement $[40,41]$. Research on the socioeconomic patterns of social determinants of health and the consequences of (poor) health, suggest that the most privileged would experience fewer and less severe negative educational consequences of prior mental health problems than their less advantaged peers [32, 42, 43].

Accordingly, it is likely that the risk of adverse future outcomes for mentally distressed adolescents differ depending on social background and is greatest among youths from low socioeconomic status (SES) families $[44,45]$. However, it is not clear whether mental health status is consistently related to academic achievement across socioeconomic groups. This knowledge gap is especially pronounced in the Swedish context despite the contribution of Brännlund and Edlund (2020), who concluded that family socioeconomic background moderate the relationship between poor mental health in childhood/adolescence and later graduation failure and grade points in upper secondary school students, especially among girls [46].

Systematic reviews of research on emotional problems and school outcomes in children and adolescents conclude that existing evidence to a high degree rely on cross-sectional studies (see e.g. $[15,47])$. In order to establish directions of associations, prospective longitudinal designs are needed. Longitudinal research is also important to prevent potential negative or positive affectivity, which would occur if, for example, adolescents with poor mental health were more likely to report poor school performance, or if their healthy peers tend to overrate their achievements [20, 48]. Affectivity can be minimised by examining register data rather than 
self-reported information. The present study is based on longitudinal register data with yearly observations.

The aim of the present study is to investigate social gradients in the prospective association between childhood/youth mental disorder and academic achievement at age 15-16 in Swedish boys and girls.

\section{Methods}

The study is based on administrative data from the Umeå SIMSAM Lab. Umeå SIMSAM Lab is specifically designed to investigate questions on children's health and well-being [49]. Data are longitudinal and incorporate medical and social individual-level information from several registers covering the entire Swedish population between 1960 and 2010. Each individual is assigned a unique and fully anonymised personal identification number that links them to family members across registers. In addition to the Total Population Register, this study also used information from other registers as described below. The Regional Ethical Vetting Board in Umeå approved all research based on data from the Umeå SIMSAM Lab, including the present study (Dnr.2010-157-31).

\section{Population}

The population comprises all individuals born between 1990 and 1994 who (according to the Total Population Register) were alive and resided in Sweden in $2010(N=$ 642,558 boys $=51.38 \%$ ). These individuals are hereafter referred to as index persons. As all data were retrieved from registers, no active consent was given by participants.

\section{Outcome}

Academic achievement is defined as the sum of the index person's 16 best subject grades during the final year of compulsory schooling (9th grade), when the index persons were 15-16 years old. Data were drawn from the Swedish National Agency for Education's Pupil Register.

For each subject, a student is assigned a grade ranging from 0 to 20. The summed grade points thus range from 0 to 320 and indicate the child's general academic achievement (performance, effort, and ambition). This variable was standardised into $\mathrm{z}$-scores $($ mean $=0$, and standard deviation $=1$ ).

\section{Predictors}

In the current study, we use the term 'mental disorder' to conceptualise the included indicators of poor mental health: psychiatric hospitalisation events and psychoanaleptic drug prescriptions. These are further described below. Both hospitalisation and medical treatment indicate relatively severe conditions and should therefore neither be conceptualised as, for example, 'poor mental health' in a broad sense, nor as the more serious conditions of 'mental illness' [1]. Another possible term would have been 'psychiatric disorder'. However, as the ICD 10 uses the term mental disorders [50], we believe that consistency in conceptualisation is preferred. The term mental disorder has also been used in a recent similar study [51].

Psychiatric hospitalisations indicates the number of hospitalisation events due to a main diagnosis of mental disorder according to the International Classification of Disease (ICD-9: 290-319, ICD-10: F00-F99), obtained from the Swedish National Patient Register (NPR) [52]. This variable indicates the total number of hospitalisation events between birth (1990-1994) until the year before the index person received their compulsory school grades (2005-2009). In Sweden, children with mental health problems receive outpatient care at primary care centres or psychiatric specialist care units. Psychiatric hospitalisations occur only in response to acute events (e.g., suicidal events) or if a patient's health status becomes significantly impaired despite outpatient treatment. Psychiatric hospitalisations therefore corresponds to one psychiatric inpatient care event, which indicates severe psychiatric disorder.

Psychoanaleptic drug prescriptions. To complement the hospitalisation data and detect individuals with less severe psychiatric health problems, records of prescription drug sales were retrieved from the Swedish Prescribed Drug Register (PDR). These data included details of the patient and the active substance prescribed, classified using the Anatomical Therapeutic Chemical (ATC) Classification System. The information from the PDR was only available to us for the years 2005-2010, when the index persons were 11-16 years of age. The psychoanaleptic drug prescription indicator indicates whether the individual under consideration was prescribed any medication with an ATC classification of N06 (psychoanaleptics) at least once over this 5-year period (no/yes). This category includes Attention-Deficit/ Hyperactivity Disorder (ADHD) medications and drugs for sleeping problems and anxiety. Drug prescription has been used as an indicator of poor mental health in similar studies [53].

\section{Indicators of socioeconomic position}

Parental level of education is a widely used indicator of family socioeconomic position (SEP) [54], especially in studies on academic achievement $[55,56]$. In this study, parental level of education was operationalised as the highest level of education attained by either parent when the child was 7 years old. Prior to 2018, children in Sweden started school (year 1) at age 7 years (after 2018, compulsory schooling start at age 6). The indicator is 
based on the status of the index person's parent (either mother or father) with the highest education level. Four levels were defined: (1) compulsory school (1st-9th grade); (2) 2 years' upper secondary education; (3) 3 years' upper secondary education; and, (4) postsecondary education. These four groups correspond to the existing levels of education in Sweden when the parents attended upper secondary school. A 2 year upper secondary education includes vocational training whereas 3 years of upper secondary education qualifies for tertiary studies. Data were obtained from the Longitudinal Integration Database for Health and Labour Market Studies (LISA) [57].

Family income was used as an alternative indicator of socioeconomic position (data from LISA database). It measures the total earned income for both the father and the mother from the year of the index person's birth to the year of their compulsory school graduation. The total earned income for each year was summed and then averaged over the years (16) since the index person's birth. Index persons were grouped into quartiles based on the income variable, using a similar approach to that applied for the parental education variable.

\section{Covariates}

Four covariates potentially related to mental disorder and academic achievement were included: maternal country of birth (Sweden or outside of Sweden; data obtained from the Medical Birth Register where only maternal country of birth is registered); family type (whether the child lived with both biological parents in the year of compulsory school graduation or not; Total Population Register); number of siblings (Total Population Register), and maternal and paternal psychiatric morbidity. The latter two covariates use data from the NPR and indicate (no/yes) whether the corresponding parent had been hospitalised with a main diagnosis of mental disorder (ICD-9: 290-319, ICD-10: F00-F99) since the birth of the index person. Gender (boy/girl) was used as both a covariate and a stratification variable (data from the Total Population Register).

\section{Statistical analyses}

Analysis of variance (ANOVA) and $t$-tests were used to examine mean differences in the main variables of the study between boys and girls in different socioeconomic positions. Bivariate and multivariate linear regression were used to investigate associations between the indicators of mental disorder and grade points. Outcomes were analysed using four models. Model 1a reflects the association between psychiatric hospitalisation events and school grades only. Model $1 \mathrm{~b}$ is adjusted for all the covariates. Model 2a shows the association between psychoanaleptic drug prescriptions and school grades, and model $2 \mathrm{~b}$ is adjusted for all the covariates. Because we examine complete cohorts rather than a sample of the total population, $p$-values and standard errors are superfluous and not presented. Instead, beta coefficients of $z$ scores of grade points with upper and lower 95\% confidence intervals are presented. Interaction analyses were performed using the fully adjusted models (model $1 \mathrm{~b}$ and model $2 \mathrm{~b}$ ) to compare the effects of mental disorders on grade points between children in different social groups and between boys and girls within these groups. Stratified analyses were performed when interaction effects of $p<0.05$ were identified. All analyses were performed in Stata v. 14.

\section{Results}

Table 1 shows a stepwise social gradient in mental disorders where mean number of psychiatric hospitalisation events as well as proportions of prescribed psychoanaleptic medication decreased by increased parental level of education and income. Similarly, there was a clear gradient in academic achievement (not shown in table). A one-way ANOVA was performed to compare the mean grade points between the four groups of parental level of education (compulsory, $M=-0.62, \mathrm{SD}=1.06,2$ year upper secondary, $M=-0.279, \mathrm{SD}=0.930,3$ year secondary, $M=0.034, \mathrm{SD}=.90$, post-secondary, $M=$ $0.391, \mathrm{SD}=0.872$ ), which revealed a statistically significant difference $(F(3,579,851)=27,146.40, p<0.001$, $\eta^{2}=12.3$. Thus, $12.3 \%$ of the total variance in academic achievement was accounted for by group membership (results from the Tukey post hoc test are available in Additional file 1). Given the benchmarks provided by Cohen (1988) to define small $\left(\eta^{2}=0.01\right)$, medium $\left(\eta^{2}=\right.$ $0.06)$, and large $\left(\eta^{2}=0.14\right)$ effects, these differences are quite large.

A second one-way ANOVA was performed to compare the mean grade points between the 1 st $(\mathrm{M}=-0.361, \mathrm{SD}=$ $1.14)$, 2nd $(\mathrm{M}=-0.138, \mathrm{SD}=0.965)$, 3rd $(\mathrm{M}=0.048, \mathrm{SD}=$ $0.879)$, and 4th $(\mathrm{M}=0.395, \mathrm{SD}=0.861)$ income quartile, which also showed a statistically significant difference $(\mathrm{F}$ $(3,605,457)=16,371.32, p<0.001, \mathrm{~h} 2=0.075$. Here, $7.5 \%$ of the total variance in academic achievement was accounted for by group membership, indicating a medium-sized effect. These results show that the variance in academic achievement to a larger degree is explained by parental level of education $(12.3 \%)$ than family income (7.5\%).

Additionally, girls obtained higher grade point scores $(M=0.168, S D=0.001)$ than boys $(M=-0.162, S D=$ $0.001), t(605459)=-1.3, p<.001, d=0.33)$. The two indicators of mental disorders were slightly more common in girls than in boys; girls $(M=0.028, \mathrm{SD}=0.26)$ had more days hospitalised than boys $(M=0.019, S D=0.24)$, $t(643555)=-20.3, p<0.001, d=0.36$ and a higher 
Table 1 Population characteristics and mental disorder indicators related to study variables

\begin{tabular}{|c|c|c|c|c|}
\hline & \multicolumn{2}{|l|}{ All } & \multicolumn{2}{|l|}{ Mental disorder indicators } \\
\hline & $\mathrm{N}$ & $\%$ of total & $\begin{array}{l}\text { Psychiatric hospitalisation } \\
\text { events, } m \text { (s.d.) }\end{array}$ & $\begin{array}{l}\text { Psychoanaleptics } \\
\text { prescription, } \%\end{array}$ \\
\hline Total & 643558 & 100.00 & $0.023(0.25)$ & 6.19 \\
\hline \multicolumn{5}{|l|}{ Sex } \\
\hline Male & 330667 & 51.38 & $0.019(0.24)$ & 5.56 \\
\hline Female & 312891 & 48.62 & $0.028(0.26)$ & 6.86 \\
\hline \multicolumn{5}{|l|}{ Parental level of education } \\
\hline Compulsory & 39296 & 6.57 & $0.038(0.29)$ & 8.67 \\
\hline Upper secondary two year & 212933 & 35.61 & $0.027(0.30)$ & 7.58 \\
\hline Upper secondary three year & 98437 & 16.46 & $0.021(0.20)$ & 5.58 \\
\hline Post-secondary & 247257 & 41.35 & $0.021(0.23)$ & 5.48 \\
\hline Missing (\% of total) & 45635 & 13.10 & $0.012(0.16)$ & 2.76 \\
\hline \multicolumn{5}{|l|}{ Family income (quartiles) } \\
\hline $1^{\text {st }}$ quartile & 160893 & 25.00 & $0.026(0.24)$ & 6.29 \\
\hline $2^{\text {nd }}$ quartile & 160886 & 25.00 & $0.024(0.21)$ & 7.42 \\
\hline $3^{\text {rd }}$ quartile & 160890 & 25.00 & $0.021(0.31)$ & 5.92 \\
\hline $4^{\text {th }}$ quartile & 160888 & 25.00 & $0.021(0.23)$ & 5.37 \\
\hline \multicolumn{5}{|l|}{ Family Type } \\
\hline Both biological parents & 450588 & 70.01 & $0.019(0.20)$ & 5.39 \\
\hline Not both biological parents & 161996 & 25.17 & $0.039(0.37)$ & 9.22 \\
\hline Missing (\% of total) & 30974 & 4.82 & $0.004(0.06)$ & 2.03 \\
\hline \multicolumn{5}{|l|}{ Number of siblings } \\
\hline 0 & 38284 & 5.95 & $0.022(0.23)$ & 5.58 \\
\hline 1 & 229292 & 35.63 & $0.020(0.28)$ & 5.44 \\
\hline 2 & 193258 & 30.00 & $0.021(0.21)$ & 5.89 \\
\hline 3 & 96321 & 14.50 & $0.025(0.23)$ & 6.83 \\
\hline 4 & 45100 & 7.00 & $0.033(0.26)$ & 8.04 \\
\hline 5 & 21243 & 3.30 & $0.035(0.31)$ & 8.84 \\
\hline $6+$ & 20060 & 3.12 & $0.039(0.30)$ & 8.77 \\
\hline \multicolumn{5}{|l|}{ Mother's birth country } \\
\hline Sweden & 496470 & 77.15 & $0.024(0.26)$ & 6.69 \\
\hline Not Sweden & 70535 & 10.96 & $0.027(0.24)$ & 5.17 \\
\hline Missing (\% of total) & 76553 & 11.90 & $0.017(0.19)$ & 3.93 \\
\hline \multicolumn{5}{|l|}{ Maternal psychiatric morbidity } \\
\hline Yes & 24727 & 3.84 & $0.064(0.39)$ & 13.62 \\
\hline \multicolumn{5}{|l|}{ Paternal psychiatric morbidity } \\
\hline Yes & 24962 & 3.88 & $0.048(0.29)$ & 12.33 \\
\hline
\end{tabular}

frequency of psychoanaleptic drug prescription $\chi^{2}(1, N=$ $643,557)=451.1, p<0.001, d=0.05$. While the differences in grade point scores and hospitalisation events were small to medium-sized, the differences in psychoanaleptic drug prescription were very small [58] .

The regression analyses show that both indicators of mental disorder were associated with reduced academic achievement. The unadjusted and adjusted Beta coefficients for psychiatric hospitalisation were -0.36 $(\mathrm{CI}=-0.38,0.35)$ and $-0.33(\mathrm{CI}=-0.35,-0.33)$ respectively. In other words, each hospitalisation event due to a mental disorder was associated with a decrease in grade points of 0.33 standard deviations when taking a range of possible confounders into account. The corresponding coefficients for being prescribed psychoanaleptics were $0.75(\mathrm{CI}=-0.76,--0.74)$ and $-0.70(\mathrm{CI}=-0.71,--0.69)$. 
Given the identified gender pattern in both the predictors and the outcome, stratified analyses by gender and SEP were performed. As shown in Tables 2 and 3, mental disorder was more strongly associated with reduced grades among boys than among girls regardless of SEP category. The negative association between psychiatric hospitalisation and grade points was strongest among boys in the highest SEP. Among girls, the association was strongest in the second highest SEP.

To further explore these gender and SEP patterns, interaction analyses were performed using the highest SEP categories as reference. As shown in Table 4 and 5, the interaction effects of SEP and psychiatric hospitalisation were more pronounced among girls than among boys. The grade points of girls in the mid SEP groups were particularly negatively affected by psychiatric hospitalisation. For example, hospitalisation events among girls whose parents had completed 3 years of upper secondary education was associated with -0.15 standard deviations in grade points per event, compared to those with parents with a post-secondary education. The corresponding result for girls in the second family income quartile was --0.13. Table 4 further shows that this Ushaped pattern among girls also was detected for psychoanaleptic medication prescription and the SEP indicator of parental level of education. No interactions were identified among boys with regards to psychoanaleptic medication prescription. Worth noting are the statistically significant positive coefficients among boys. Compared to their high SEP peers, psychiatric hospitalisation was associated with an increase in grade points by 0.08 standard deviations per each hospitalisation event for boys in the two-year upper secondary parental education category. Among boys in the lowest family income quartile, the grade points improved by 0.13 standard deviations per each hospitalisation event. The interaction analyses for family income and prescription of psychoanaleptics showed a linear pattern; the interaction decreased by increasing level of income, primarily among girls (Table 5).

\section{Discussion}

This study aimed to investigate social gradients in the association between mental disorder in childhood/adolescence and academic achievement at 15-16 years of age. Both indicators of mental disorder (hospitalisation due to a psychiatric diagnosis and prescription of psychoanaleptics) were associated with lower grade points in all SEP groups. These findings confirm previous results $[5,17,20,21]$. Interaction analyses showed that level of parental education primarily moderated the association between mental disorder and academic achievement among girls. This is consistent with the conclusions of Brännlund and Edlund (2020) although the present study analysed the social gradient more closely than was done in their work, for example by using a four-category measure of parental education rather than two-categories, and also family income. Girls whose parents had completed 3 years of upper secondary education or belonged to the second family income quartile experience the most severe adverse effects on school grades due to mental disorder. However, it should be noted that boys' grades were by no means unaffected by previous mental disorder. In contrast to several other studies $[17,19,37,38]$, our study showed stronger negative associations between mental disorder and grade points in boys than in girls. However, there appears to be no typical social gradient in this association among boys although some findings deserve attention, which will be discussed below.

Based on previous findings $[44,45]$ and theory on the importance of access to cultural and economic resources [56], we expected that both boys and girls in the lowest SEP categories would exhibit the strongest adverse effects on school grades due to mental disorder, and that severity would decline as level of parental education and income increased. Instead, the findings indicate a $\mathrm{U}$ shaped pattern among girls and no or inverse gradient in boys. Several interpretations of our findings are possible. First, low SEP families might experience elevated and varying types of stressors, combined with greater barriers to accessing resources relative to other groups; this is likely to affect both mental health and school achievement $[59,60]$. For example, because children of low SEP parents already have the lowest level of achievement of the four groups, it is possible that they do not have much further to fall even when exposed to adverse circumstances. This potential 'floor effect' was identified in a European study on the educational consequences of parental divorce; divorce does not worsen the school outcomes of children from poorly educated families because they already have limited educational opportunities [61].

Second, it is possible that children and adolescents with poor mental health from less educated families actually benefit more from hospital admission and medicine prescription than their more advantaged peers do. School success has, for example, been identified as a positive effect of mental health medication [62]. The unexpected results for boys with regard to indications of improved grade points due to hospitalisation for the 2nd categories of both SEP measures, might reflect this. However, more research is required to understand this interaction further and to determine whether this effect is equally strong in all socioeconomic groups.

Third, school-related stress may help explain the identified drop in academic achievement among girls of parents with intermediate levels of education. It has been 


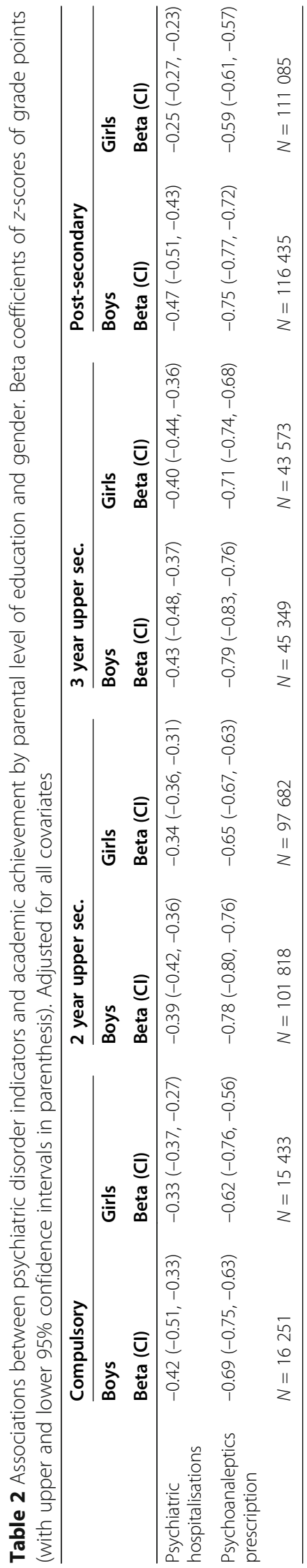




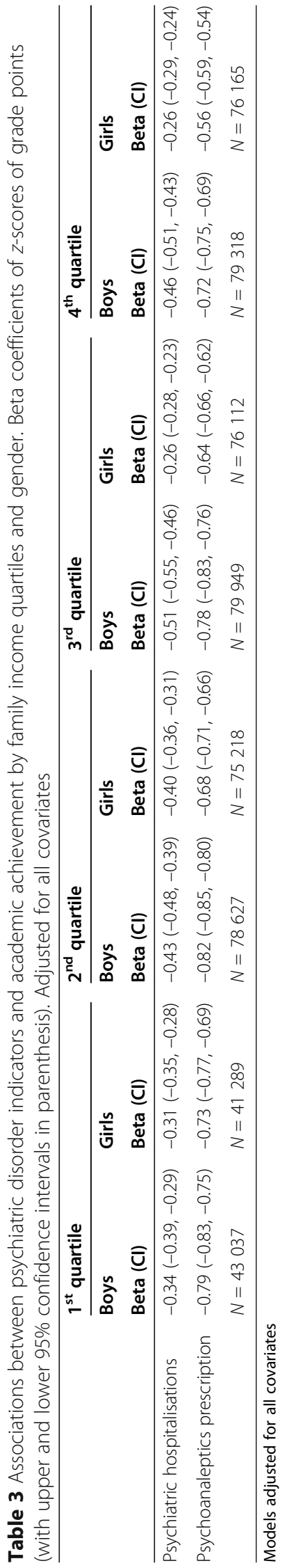


Table 4 Models displaying interactions between mental disorder indicators and parents' level of education for boys and girls. Beta coefficients of z-scores of grade points (with upper and lower 95\% confidence intervals in parenthesis)

\begin{tabular}{|c|c|c|c|c|}
\hline & Boys & & Girls & \\
\hline & $\begin{array}{l}\text { Model 1a } \\
\text { Beta (Cl) }\end{array}$ & $\begin{array}{l}\text { Model 1b } \\
\text { Beta (Cl) }\end{array}$ & $\begin{array}{l}\text { Model 2a } \\
\text { Beta }(\mathrm{Cl})\end{array}$ & $\begin{array}{l}\text { Model 2b } \\
\text { Beta (Cl) }\end{array}$ \\
\hline Parental level of education & & & & \\
\hline Compulsory & $-0.85(-0.87,-0.84)$ & $-0.85(-0.86,-0.83)$ & $-0.89(-0.90,-0.87)$ & $-0.87(-0,88,-0.85)$ \\
\hline Upper secondary two year & $-0.62(-0.63,-0.61)$ & $-0.60(-0.61,-0.60)$ & $-0.62(-0.63,-0.62)$ & $-0.61(-0.62,-0.31)$ \\
\hline Upper secondary three year & $-0.34(-0.35,-0.33)$ & $-0.33(-0.34,-0.32)$ & $-0.33(-0.34,-0.32)$ & $-0.32(-0.33,-0.31)$ \\
\hline Post-secondary (Ref.) & 0 & 0 & 0 & 0 \\
\hline Psychiatric hospitalisations & $-0.43(-0.50,-0.36)$ & & $-0.25(-0.27,-0.23)$ & \\
\hline$\times$ Compulsory & $0.04(-0.05,0.12)$ & & $-0.10(-0.15,-0.04)$ & \\
\hline$\times$ Upper secondary two year & $0.08(0.03,0.13)$ & & $-0.09(-0.12,-0.06)$ & \\
\hline$\times$ Upper secondary three year & $0.04(-0.30,0.11)$ & & $-0.15(-0.20,-0.11)$ & \\
\hline$\times$ Post-secondary (Ref.) & 0 & & 0 & \\
\hline Psychoanaleptics prescription & & $-0.75(-0,77,-0.73)$ & & $-0.59(-0.61,-0.56)$ \\
\hline$\times$ Compulsory & & $0.03(-0.02,0.08)$ & & $-0.09(-0.14,-0.04)$ \\
\hline$\times$ Upper secondary two year & & $-0.04(-0.07,-0.00)$ & & $-0.08(-0.11,-0.05)$ \\
\hline$\times$ Upper secondary three year & & $-0.04(-0.08,0.00)$ & & $-0.12(-0.16,-0.08)$ \\
\hline × Post-secondary (Ref.) & & 0 & & 0 \\
\hline N & 279853 & & 267772 & \\
\hline
\end{tabular}

Confidence intervals that do not include 0 indicate that estimates are statistically significant at the $5 \%$ level $(p<0.05)$. Model $1 \mathrm{a}-1 \mathrm{~b}$ displays the results for boys, model $2 \mathrm{a}-2 \mathrm{~b}$ for girls. Models adjusted for all covariates

Table 5 Models displaying interactions between psychiatric disorder indicators and family income quartiles for boys and girls. Beta coefficients of z-scores of grade points (with upper and lower 95\% confidence intervals in parenthesis)

\begin{tabular}{|c|c|c|c|c|}
\hline & \multicolumn{2}{|l|}{ Boys } & \multicolumn{2}{|l|}{ Girls } \\
\hline & $\begin{array}{l}\text { Model 1a } \\
\text { Beta }(\mathrm{Cl})\end{array}$ & $\begin{array}{l}\text { Model 1b } \\
\text { Beta }(\mathrm{Cl})\end{array}$ & $\begin{array}{l}\text { Model 2a } \\
\text { Beta }(\mathrm{Cl})\end{array}$ & $\begin{array}{l}\text { Model 2b } \\
\text { Beta }(\mathrm{Cl})\end{array}$ \\
\hline \multicolumn{5}{|l|}{ Family income } \\
\hline $1^{\text {st }}$ quartile & $-0.32(-0.33,-0.31)$ & $-0.31(-0.32,-0.30)$ & $-0.31(-0.32,-0.30)$ & $-0.30(-0,31,-0.28)$ \\
\hline $2^{\text {nd }}$ quartile & $-0.26(-0.27,-0.25)$ & $-0.25(-0.26,-0.24)$ & $-0.25(-0.26,-0.24)$ & $-0.24(-0.25,-0.23)$ \\
\hline $3^{\text {rd }}$ quartile & $-0.18(-0.19,-0.17)$ & $-0.17(-0.18,-0.16)$ & $-0.16(-0.17,-0.15)$ & $-0.15(-0.16,-0.15)$ \\
\hline $4^{\text {th }}$ quartile (Ref.) & 0 & 0 & 0 & 0 \\
\hline Psychiatric hospitalisations & $-0.46(-0.51,-0.41)$ & & $-0.26(-0.28,-0.23)$ & \\
\hline$\times 1^{\text {st }}$ quartile & $0.13(0.06,0.20)$ & & $-0.06(-0.10,-0.02)$ & \\
\hline$\times 2^{\text {nd }}$ quartile & $0.04(-0.03,0.10)$ & & $-0.13(-0.17,-0.09)$ & \\
\hline$\times 3^{\text {rd }}$ quartile & $-0.02(-0.10,0.04)$ & & $0.00(-0.03,0.04)$ & \\
\hline$\times 4^{\text {th }}$ quartile (Ref.) & 0 & & 0 & \\
\hline Psychoanaleptics prescription & & $-0.70(-0,77,-0.73)$ & & $-0.55(-0.57,-0.52)$ \\
\hline$\times 1^{\text {st }}$ quartile & & $-0.08(-0.12,-0.04)$ & & $-0.18(-0.22,-0.14)$ \\
\hline$\times 2^{\text {nd }}$ quartile & & $-0.10(-0.14,-0.06)$ & & $-0.12(-0.15,-0.08)$ \\
\hline$\times 3^{\text {rd }}$ quartile & & $-0.05(-0.09,-0.01)$ & & $-0.07(-0.11,-0.04)$ \\
\hline$\times 4^{\text {th }}$ quartile (Ref.) & & 0 & & 0 \\
\hline N & 279853 & & 267772 & \\
\hline
\end{tabular}

Confidence intervals that do not include 0 indicate that estimates are statistically significant at the $5 \%$ level $(p<0.05)$. Model $1 a-1 b$ displays the results for boys, model $2 \mathrm{a}-2 \mathrm{~b}$ for girls. Models adjusted for all covariates 
suggested that school-related demands explain the higher incidence of poor mental health in adolescent girls compared to boys [38]. It has also been established that while school-related stress is prevalent in youths from mid/high socioeconomic backgrounds (especially girls), those from low socioeconomic backgrounds are more stressed about relationships and lack of money [63-66]. There might also be an incongruence between ambition and available resources for girls in the mid SEP categories. In other words, they and their parents might experience pressure and have high ambitions relating to school performance, but lack familial resources (i.e. cultural and economic capital) to "buffer" the negative impact of mental disorder on the child's school achievement [56, 63, 67]. Such "buffers" may include familial or social academic support networks, private tutors, or other privately financed educational interventions [67]. A similar argument would be probable for income categories; a child whose parents have high income but relatively little experience of studying will probably have other kinds of academic socialisation and adopt different study strategies to a child whose parents are more highly educated but less well-paid, leading to differences in school grades.

Although level of education typically represents access to cultural capital relevant to academic achievement, educational outcomes must be considered in combination with resources such as income [56]. These SEP indicators are typically highly correlated. However, the difference between parental education and family income can be explained by supposing that parental education represents a type of cultural capital necessary for children's academic achievement that extends over and beyond income. For example, blue collar professions do not require extensive theoretical study but can nevertheless be well-paid, while other occupations that require longer educations provide relatively low wages [68].

With regard to the gender patterns identified in this study, it is noteworthy, that despite Sweden's high international rankings with regard to gender equality, income levels and the labour market are strongly gendered in Sweden; on a group level, women are disadvantaged relative to men [69]. It is likely that these circumstances influence the aspirations of girls and boys. Although girls receive better grade points than boys do, achieving good grades may be seen as a more important route to future financial security and labour market opportunities for girls than for boys. This might lead to greater stress about school performance among girls from mid SEP backgrounds even if they generally show better school results than their male peers do.

The strengths of this study include its use of high quality data and a large sample size, which enable broad generalisation. The use of register data reduces the risk of recall and selection bias. However, some limitations deserve attention. First, the chosen indicators of mental disorder: psychiatric hospitalisation is rare and is a rather crude indicator because it can result from a wide range of disparate diagnoses including drug abuse, depression, and schizoaffective disorders. Prescription of mental health medication is more common but is still a relatively imprecise measure of poor mental health. Our conclusions therefore relate to mental disorder in its broadest sense. We acknowledge that other types of mental health problems are not captured by these indicators and that we cannot distinguish which disorder, if any, that is most strongly related to academic achievement. Therefore, given the limitations of hospitalisation and medication as indicators of mental disorders, and that many children might never receive the appropriate attention and/or diagnosis, future studies should differentiate between types of diagnoses and also include symptomatology. Second, the categorisation of family income based on quartiles likely does not capture the same people as within the education group. Hence, these are not directly comparable.

\section{Conclusions}

This study suggests that, in contrast to an expected linear social gradient, there is a U-shaped social gradient in the relationship between mental disorder in childhood or adolescence and grade points at age 15/16 years, especially among girls. Specifically, the school grades of girls from families of intermediate socioeconomic position were more strongly affected by mental disorder (as indicated by hospitalisation and prescription of psychoanaleptic medication) than those of their peers in the low and high SEP categories. This study shows the importance of recognising several indicators of socioeconomic position as well as gender when investigating links between mental health and academic achievement. Future research should address both socioeconomic background and gender disparities to clarify the links between mental health and schoolrelated outcomes in children and adolescents.

\section{Abbreviations \\ ADHD: Attention-deficit/hyperactivity disorder; ATC: Anatomical therapeutic chemical classification system; ICD: International classification of disease; LISA: Longitudinal integration database for health and labour market studies; NPR: Swedish national patient register; PDR: Swedish prescribed drug register; SEP: Socioeconomic position}

\section{Supplementary Information}

The online version contains supplementary material available at https://doi. org/10.1186/s12888-021-03448-z.

\section{Additional file 1.}

Acknowledgements

The Umeå SIMSAM Lab data infrastructure used in this study was developed with support from the Swedish Research Council and strategic funds from Umeå University. 


\section{Authors' contributions}

$E L, C B$ and MS developed the rationale for the study. CB and EL analysed and interpreted data as well as wrote up the initial draft of the manuscript. MS reviewed subsequent drafts.MS is the Principal Investigator of the project in which this study is included. All authors read and approved the final manuscript.

\section{Authors' information}

Evelina Landstedt, Associate Professor in Public Health and holds a position as Senior Lecturer in Social work at Karlstad University. She is also affiliated to the Department of Social Work at Umeå University and Centre for Research on Child and Adolescent Mental Health, Karlstad University. Cristian Bortes has a Master of Public Health and is currently a doctoral candidate in Social Work at Umeå University. Mattias Strandh is Professor in Social Work at Umeå University and is affiliated to Centre for Research on Child and Adolescent Mental Health, Karlstad University.

\section{Funding}

The research was funded through grants from the Swedish Research Council (Dnr: 2014-1992) and Markus and Marianne Wallenbergs fund (Dnr: 2014.0154). The funding body supports the overall purpose and design of the study bus has not been involved in collection, analysis or interpretations of data, or in the process of writing the manuscript. Open Access funding provided by Umea University.

\section{Availability of data and materials}

Data is not publicly available. Please contact Umeå SimSam Lab for further information on data availability.

\section{Declarations}

\section{Ethics approval and consent to participate}

The Regional Ethical Vetting Board in Umeå approved all research based on data from the Umeå SIMSAM Lab, including the present study (Dnr.2010157-31). The study is based on registry data. Informed consent of participation is therefore not applicable.

\section{Consent for publication}

Not applicable.

\section{Competing interests}

None.

\section{Author details \\ 'Department of Social and Psychological Studies, Karlstad University, and Adolescent Mental Health, Karlstad University, SE-651 88 Karlstad, Sweden \\ Received: 5 November 2020 Accepted: 27 August 2021 Published online: 06 September 2021} Universitetsgatan 2, SE-651 88 Karlstad, Sweden. ${ }^{2}$ Department of Social Work, Umeå University, SE-907 87 Umeå, Sweden. ${ }^{3}$ Centre for Research on Child

\section{References}

1. Granlund M, Imms C, King G, Andersson AK, Augustine L, Brooks R, et al. Definitions and operationalization of mental health problems, wellbeing and participation constructs in children with ndd: distinctions and clarifications. Int J Environ Res Public Health. 2021;18(4):1656. https://doi. org/10.3390/ijerph18041656.

2. Currie J, Stabile M, Manivong P, Roos LL. Child health and young adult outcomes. J Hum Resour. 2010;45(3):517-48.

3. Layard R, Clark AE, Cornaglia F, Powdthavee N, Vernoit J. What predicts a successful life? A life-course model of well-being. Econ J. 2014;124(580): F720-38.

4. Arnold LE, Hodgkins P, Kahle J, Madhoo M, Kewley G. Long-term outcomes of ADHD: academic achievement and performance. J Atten Disord. 2020; 24(1):73-85. https://doi.org/10.1177/1087054714566076.

5. Fletcher JM. Adolescent depression and educational attainment: results using sibling fixed effects. Health Econ. 2010;19(7):855-71. https://doi.org/1 $0.1002 /$ hec. 1526
6. Fryers T, Brugha T. Childhood determinants of adult psychiatric disorder. Clin Pract Epidemiol Ment Health. 2013;9:50.

7. Acacio-Claro PJ, Doku DT, Koivusilta LK, Rimpela AH. How socioeconomic circumstances, school achievement and reserve capacity in adolescence predict adult education level: a three-generation study in Finland. Int J Adolesc Youth. 2018;23(3):382-97. https://doi.org/10.1080/02673843.2017.1389759.

8. Almquist YB, Landstedt $E$, Jackisch J, Rajaleid K, Westerlund $H$, Hammarström A. Prevailing over adversity: factors counteracting the longterm negative health influences of social and material disadvantages in youth. Int J Environ Res. 2018;15(9).

9. Bor W, Dean AJ, Najman J, Hayatbakhsh R. Are child and adolescent mental health problems increasing in the 21st century? A systematic review. Aust N Z J Psychiatry. 2014;48(7):606-16. https://doi.org/10.1177/ 0004867414533834

10. Bremberg S. Mental health problems are rising more in Swedish adolescents than in other Nordic countries and the Netherlands. Acta Paediatr. 2015;104(10):997-1004.

11. OECD. Improving schools in Sweden: an OECD perspective. In. Paris: OECD Publishing; 2015

12. OECD. PISA 2015 Results in focus. Paris: OECD Publishing; 2018.

13. Wijsman LA, Warrens MJ, Saab N, van Driel JH, Westenberg PM. Declining trends in student performance in lower secondary education. Eur J Psychol Educ. 2016;31(4):595-612. https://doi.org/10.1007/s10212-015-0277-2.

14. OECD. OECD economic surveys SWEDEN. Paris: OECD Publishing; 2015.

15. Riglin $\mathrm{L}$, Petrides $\mathrm{KV}$, Frederickson $\mathrm{N}$, Rice F. The relationship between emotional problems and subsequent school attainment: a meta-analysis. J Adolesc. 2014;37(4):335-46. https:/doi.org/10.1016/j.adolescence.2014.02.010.

16. Needham BL. Adolescent depressive symptomatology and young adult educational attainment: an examination of gender differences. J Adolesc Health. 2009;45(2):179-86. https://doi.org/10.1016/j.jadohealth.2008.12.015.

17. Deighton J, Humphrey N, Belsky J, Boehnke J, Vostanis P, Patalay P. Longitudinal pathways between mental health difficulties and academic performance during middle childhood and early adolescence. Br J Dev Psychol. 2018;36(1):110-26. https://doi.org/10.1111/bjdp.12218.

18. Awadalla S, Davies EB, Glazebrook C. A longitudinal cohort study to explore the relationship between depression, anxiety and academic performance among Emirati university students. BMC Psychiatry. 2020;20(1):448. https:// doi.org/10.1186/s12888-020-02854-z.

19. Esch P, Bocquet V, Pull C, Couffignal S, Lehnert T, Graas M, et al. The downward spiral of mental disorders and educational attainment: a systematic review on early school leaving. BMC Psychiatry. 2014;14(1):237. https://doi.org/10.1186/s12888-014-0237-4.

20. Quiroga CV, Janosz M, Bisset S, Morin AJS. Early adolescent depression symptoms and school dropout: mediating processes involving self-reported academic competence and achievement. J Educ Psychol. 2013;105(2):55260. https://doi.org/10.1037/a0031524.

21. Suldo S, Thalji A, Ferron J. Longitudinal academic outcomes predicted by early adolescents' subjective well-being, psychopathology, and mental health status yielded from a dual factor model. J Posit Psychol. 2011;6(1):1730. https://doi.org/10.1080/17439760.2010.536774.

22. Burt KB, Roisman Gl. Competence and psychopathology: Cascade effects in the NICHD study of early child care and youth development. Dev Psychopathol. 2010:22(3):557-67. https://doi.org/10.1017/50954579410000271.

23. Okano L, Jeon L, Crandall A, Riley A. Differential effects of internalizing behaviors on academic functioning for girls versus boys: an analysis of developmental cascades from elementary to high school. Dev Psychopathol. 2020;32(2):751-64. https://doi.org/10.1017/50954579419000737.

24. Defoe IN, Farrington DP, Loeber R. Disentangling the relationship between delinquency and hyperactivity, low achievement, depression, and low socioeconomic status: analysis of repeated longitudinal data. J Crim Justice. 2013;41(2):100-7. https://doi.org/10.1016/j.jcrimjus.2012.12.002.

25. Panayiotou M, Humphrey N. Mental health difficulties and academic attainment: evidence for gender-specific developmental cascades in middle childhood. Dev Psychopathol. 2017;30:523-38.

26. Weeks M, Ploubidis GB, Cairney J, Wild TC, Naicker K, Colman I. Developmental pathways linking childhood and adolescent internalizing, externalizing, academic competence, and adolescent depression. J Adolesc. 2016;51:30-40. https://doi.org/10.1016/j.adolescence.2016.05.009.

27. McLeod JD, Fettes DL. Trajectories of failure: the educational careers of children with mental health problems. Am J Sociol. 2007;113(3):653-701. https://doi.org/10.1086/521849. 
28. Fletcher JM. Adolescent depression: diagnosis, treatment, and educational attainment. Health Econ. 2008;17(11):1215-35. https://doi.org/10.1002/hec.1319.

29. van der Schans J, Vardar S, Çiçek R, Bos HJ, Hoekstra PJ, de Vries TW, et al. An explorative study of school performance and antipsychotic medication. BMC psychiatry. 2016;16:8.

30. Christiansen E, Agerbo E, Larsen KJ, Bilenberg N, Stenager E. Youth, suicide attempts and low level of education: a Danish historical register-based cohort study of the outcome of suicide attempt. Int J Soc Psychiatry. 2015; 61(8):802-10. https://doi.org/10.1177/0020764015597460.

31. Brännlund A, Strandh M, Nilsson K. Mental-health and educational achievement: the link between poor mental-health and upper secondary school completion and grades. J Ment Health. 2017;26(4):318-25. https:// doi.org/10.1080/09638237.2017.1294739.

32. Prince DM, Rocha A, Nurius PS. Multiple disadvantage and discrimination: implications for adolescent health and education. Soc Work Res. 2018;42(3): 169-79. https://doi.org/10.1093/swr/svy016.

33. Pryor L, Strandberg-Larsen K, Andersen AMN, Rod NH, Melchior M. Trajectories of family poverty and children's mental health: results from the Danish National Birth Cohort. Soc Sci Med. 2019;220:371-8. https://doi.org/1 0.1016/j.socscimed.2018.10.023.

34. Reiss F. Socioeconomic inequalities and mental health problems in children and adolescents: a systematic review. Soc Sci Med. 2013;90:24-31. https:// doi.org/10.1016/j.socscimed.2013.04.026

35. Voyer D, Voyer SD. Gender differences in scholastic achievement: a Meta-analysis. Psychol Bull. 2014;140(4):1174-204. https://doi.org/10.103 7/a0036620.

36. Torvik FA, Eilertsen EM, McAdams TA, Gustavson K, Zachrisson HD Brandlistuen $\mathrm{R}$, et al. Mechanisms linking parental educational attainment with child ADHD, depression, and academic problems: a study of extended families in the Norwegian mother, father and child cohort study. J Child Psychol Psychiatry. 2020;61(9):1009-18. https://doi.org/10.1111/jcpp.13197.

37. McLeod JD, Uemura R, Rohrman S. Adolescent mental health, behavior problems, and academic achievement. J Health Soc Behav. 2012;53(4):48297. https://doi.org/10.1177/0022146512462888

38. Giota J, Gustafsson J-E. Perceived academic demands, peer and teacher relationships, stress, anxiety and mental health: changes from grade 6 to 9 as a function of gender and cognitive ability. Scand J Educ Res. 2020; Published online: 13 Jul.

39. Roos LL, Hiebert B, Manivong P, Edgerton J, Walld R, MacWilliam L, et al. What is Most important: social factors, health selection, and adolescent educational achievement. Soc Indic Res. 2013;110(1):385-414. https://doi. org/10.1007/s11205-011-9936-0.

40. Ansary NS, McMahon TJ, Luthar SS. Socioeconomic context and emotionalbehavioral achievement links: concurrent and prospective associations among low- and high-income youth. J Res Adolesc. 2012;22(1):14-30. https://doi.org/10.1111/j.1532-7795.2011.00747.x

41. Jackson MI. Cumulative inequality in child health and academic achievement. J Health Soc Behav. 2015;56(2):262-80. https://doi.org/10.11 77/0022146515581857

42. McLeod JD. Why and how inequality matters. J Health Soc Behav. 2015; 56(2):149-65. https://doi.org/10.1177/0022146515581619.

43. Viner RM, Ozer EM, Denny S, Marmot M, Resnick M, Fatusi A, et al. Adolescence and the social determinants of health. Lancet. 2012;379(9826): 1641-52. https://doi.org/10.1016/S0140-6736(12)60149-4.

44. Sznitman SR, Reisel L, Romer D. The neglected role of adolescent emotional well-being in national educational achievement: bridging the gap between education and mental health policies. J Adolesc Health. 2011;48(2):135-42. https://doi.org/10.1016/j.jadohealth.2010.06.013.

45. Vander Stoep A, Weiss NS, McKnight B, Beresford SA, Cohen P. Which measure of adolescent psychiatric disorder--diagnosis, number of symptoms, or adaptive functioning--best predicts adverse young adult outcomes? J Epidemiol Community Health. 2002;56(1):56-65. https://doi. org/10.1136/jech.56.1.56

46. Brännlund A, Edlund J. Educational achievement and poor mental health in Sweden: the role of family socioeconomic resources. Educ Inq. 2020;11(1): 69-87. https://doi.org/10.1080/20004508.2019.1687079.

47. Amholt TT, Dammeyer J, Carter R, Niclasen J. Psychological well-being and academic achievement among school-aged children: a systematic review. Child Indic Res. 2020;26.

48. Chow CM, Tan CC, Buhrmester D. Interdependence of depressive symptoms, school involvement, and academic performance between adolescent friends: a dyadic analysis. Br J Educ Psychol. 2015;85(3):316-31. https://doi.org/10.1111/bjep.12075

49. Lindgren U, Nilsson K, de Luna X, Ivarsson A. Data resource profile: Swedish microdata research from childhood into lifelong health and welfare (Umeå SIMSAM Lab). Int J Epidemiol. 2016;45(4).

50. WHO. The ICD-10 Classification of Mental and Behavioural Disorders. Geneva; 1992

51. Dalsgaard S, McGrath J, Østergaard SD, Wray NR, Pedersen CB, Mortensen $\mathrm{PB}$, et al. Association of Mental Disorder in childhood and adolescence with subsequent educational achievement. JAMA Psychiatry. 2020;77(8):797-805. https://doi.org/10.1001/jamapsychiatry.2020.0217.

52. Ludvigsson JF, Andersson E, Ekbom A, Feychting M, Kim JL, Reuterwall C, et al. External review and validation of the Swedish national inpatient register. BMC Public Health. 2011;11(1). https://doi.org/10.1186/1471-2458-11-450.

53. Hollander AC. Social inequalities in mental health and mortality among refugees and other immigrants to Sweden - epidemiological studies of register data. Glob Health Action. 2013;6:1-11.

54. Nyamande FN, Mosquera PA, San Sebastián M, Gustafsson PE. Intersectional equity in health care: assessing complex inequities in primary and secondary care utilization by gender and education in northern Sweden. Int J Equity Health. 2020;19(1):159. https://doi.org/10.1186/s12939-020-01272-7.

55. Sirin SR. Socioeconomic status and academic achievement: a meta-analytic review of research. Rev Educ Res. 2005;75(3):417-53. https://doi.org/10.3102/ 00346543075003417

56. Barone C. Cultural capital, ambition and the explanation of inequalities in learning outcomes: a comparative analysis. Sociology. 2006;40(6):1039-58. https://doi.org/10.1177/0038038506069843.

57. Statistics Sweden: Longitudinal integrated database for health insurance and labour market studies (LISA). 2020.

58. Cohen J: Statistical power analysis for behavioral sciences Hillsdale: Lawrence Erlbaum associates; 1988.

59. Aneshensel CS. Toward explaining mental health disparities. J Health Soc Behav. 2009:50(4):377-94. https://doi.org/10.1177/002214650905000401.

60. Mulder BC, de Bruin M, Schreurs H, van Ameijden EJC, van Woerkum CMJ. Stressors and resources mediate the association of socioeconomic position with health behaviours. BMC Public Health. 2011;11(1). https://doi.org/10.11 86/1471-2458-11-798.

61. Bernardi F, Radl J. The long-term consequences of parental divorce for children's educational attainment. Demogr Res. 2014;30:1653-80. https://doi. org/10.4054/DemRes.2014.30.61.

62. McMillan SS, Wilson B, Stapleton H, Wheeler AJ. Young people's experiences with mental health medication: a narrative review of the qualitative literature. J Ment Health. 2020:1-15. https://doi.org/10.1080/09638237.2020.1714000.

63. Eriksen IM. Class, parenting and academic stress in Norway: middle-class youth on parental pressure and mental health. Discourse. 2020

64. Landstedt E, Gillander Gådin K. Seventeen and stressed - do gender and class matter? Health Sociol Rev. 2012;21(1):82-98. https://doi.org/10.5172/ hesr.2012.21.1.82.

65. Låftman SB, Almquist YB, Östberg V. Students' accounts of schoolperformance stress: a qualitative analysis of a high-achieving setting in Stockholm, Sweden. J Youth Stud. 2013;16(7):932-49. https://doi.org/10.1 080/13676261.2013.780126

66. West $P$, Sweeting $H$. Fifteen, female and stressed: changing patterns of psychological distress over time. J Child Psychol Psychiatry. 2003;44(3):399_ 411. https://doi.org/10.1111/1469-7610.00130

67. Madarasova Geckova A, Tavel P, van Dijk JP, Abel T, Reijneveld SA. Factors associated with educational aspirations among adolescents: cues to counteract socioeconomic differences? BMC Public Health. 2010;10(1):154. https://doi.org/10.1186/1471-2458-10-154.

68. Statistics Sweden: Lönestatistik [income statistics]. In: Statistics Sweden; 2020.

69. Magnusson C. Why is there a gender wage gap according to occupational prestige? : An analysis of the gender wage gap by occupational prestige and family obligations in Sweden. Acta Sociol. 2010;53(2):99-117.

\section{Publisher's Note}

Springer Nature remains neutral with regard to jurisdictional claims in published maps and institutional affiliations. 